\title{
Manuscript contexts and the transmission of the Agnus Castus herbal in MS Sloane $3160^{1}$
}

\author{
María José Esteve Ramos \\ Universitat Jaume I, GREMI ${ }^{2}$
}

MS Sloane 3160 is a miscellaneous volume containing one copy of the herbal Agnus Castus in Middle English. Traditionally, editions focused on texts in isolation and did not look in detail to the rest of the material, diminishing the potential of manuscript contexts in explaining how texts flow and are received by a specific audience. If we consider these groupings of texts a collective product in which all the co-texts are part of an internal dialogue, the importance of looking at the whole volume from a collective perspective becomes paramount in understanding the final aim of the compiler, and the processes of transmission of text and/or texts. The objective of this article has been to study the arrangement of the material contained in MS Sloane 3160 as a starting point to frame future comparison with manuscripts containing the same herbal. The results point to the identification of patterns which would confirm the "anthologistic impulse" (Lerer 2000). The structure of this manuscript would contain a spectrum of the most important areas that would cover the contents of a typical vademecum of the time, including religious texts, but more studies are needed in order to be able to assess these contexts in medical miscellanies. The impact and transmission of the Agnus Castus herbal needs to be studied collectively, and assessing the manuscript contexts in which the text is naturally embedded points to the right direction in understanding all the processes therein.

Keywords: miscellanea; Middle English; medical manuscripts; Agnus Castus

\footnotetext{
1 The research reported here has been funded by the Pla de Investigació de la Universitat Jaume I, grant number $18 \mathrm{I} 405$ for the Project entitled La Traducció Medieval Europea: Models i Autoritats. This grant is hereby gratefully acknowledged. I am also very much indebted to professor Jeremy Smith (University of Glasgow) for suggestions and advice.

${ }^{2}$ Grup de Recerca d'estudis Medievals Interdisciplinaris (GREMI).
}

María José Esteve Ramos, Selim24 (2019): 157-172.

ISSN 1132-631X / DOI https://doi.org/10.17811/selim.24.2019.157-174 


\section{Introduction}

The transmission of scientific texts in the medieval times was possible in many cases thanks to the multiple copies and translations contained in volumes what is generally known as miscellanea. Many of these miscellaneous collections which in English flourished specially in the fourteenth and fifteenth centuries - have been preserved and they represent the most common form under which medieval knowledge was transmitted. Important shifts in the spreading of literacy widened the audience in a remarkable way, affecting production processes and resulting in one of the most important periods for the vernacularization of the English language.

Traditionally, different miscellanea or multi-text codices collections have attracted the interest of academics, being in most cases compilations of literary material. Interest in these materials from a critical perspective has been reflected in recent publications, and the study of text transmission as a collective phenomenon has consequently begun to receive proper attention, pointing to the field as an emerging area of interest in manuscript studies. The presence of a text in a miscellaneous collection may point to a collective design and connects with the intentionality of the compiler. Hence, a text of this period should be looked at not as an individual item in an isolated environment, but as part of a collective plan and meaning:

Considerable effort has been devoted in recent years to positing varieties of connection between texts that survive together on one manuscript, and to reading these connections as aspects of a manuscript's overall conception or 'meaning'. The material forms in which multiple works have been transmitted together in a manuscript are potentially significant. The presentation of works in a collection may indicate something of the collection's status; the nature of its contents may suggest the collection's generic affiliations; annotations may indicate something of a collection's appeal to early readers. (Boffey \& Edwards 2015: 263)

Miscellaneous materials related to science and medicine have survived in larger numbers, given their practical function, but have not received proper attention from this perspective. These materials had a more pragmatic function, covering the basic medical knowledge for an average practitioner. In terms of contents, they would bear a series of canonical texts together with well-known remedies and recipes. Also, in medieval medicine, herbals such as the widely 
spread Agnus Castus would have a fundamental role in the content design of a medical miscellanea like this one.

In this article I aim at focusing on the MS Sloane 3160 containing a copy of the Agnus Castus as a starting point to study the intertextual relationships and collective function and meaning of the miscellaneous volumes this text was included in. This study is an incipient contribution to a wider scale project: the analysis of the manuscript contexts in the volumes containing a copy of the Agnus Castus in Middle English. This analysis would provide us with information to assess the impact on the transmission of this herbal, uncovering the complex relationships of the textual network involved therein, and helping to unveil the role these contexts may play in the transmission and impact of this well-known text. To this objective, many different aspects, namely related to textual, co-textual and codicological issues, need to be addressed. The need to address them systematically is a matter that has been pointed at, as Boffey \& Edwards (2015: 263) suggest: “[...] there are important additional factors that may affect or determine the forms such collections take, and there have been only intermittent attempts to identify these factors, and to clarify their roles in the shaping of the manuscripts." In this work, we will refer to some terminological issues that need to be tackled, with special attention to the notion introduced by Lerer (2003), defined as anthologistic impulse. A brief description of the Agnus Castus text follows, emphasizing the importance of this text, as the summary of the existing copies show. These copies, belonging to the Sloane Collection house in the British Library, will be considered to develop the project in full. Finally, a revision of the contents is carried out to explore the peculiarities, if any, in its particular arrangement. This arrangement will lead to further considerations related to the presence of patterns, an aspect I consider of special interest and that could help to propound a valid framework to analyze this type of compilations. In terms of further research, results would potentially lead towards a valid taxonomy to analyze the contents of scientific and medical miscellanea, specially in contrast with literary materials.

\section{Miscellanea, anthology or multi-text codex: The "anthologistic impulse"}

As it has been referred to in the Introduction, different labels are in use to name these compilations, namely miscellanea and anthology. Also, the term 
multi-tex codex, the most recent and neutral of the three, has been used by a prominent number of scholars. However, there is no solid agreement as to which one would be defining the nature of these compilations, further than the identification of miscellanea with materials that do not show any plan in their conception, and the idea of anthology related to conscious thematic arrangement, and more widely associated with literary matters. In this respect, Boffey \& Edwards point out:

The lack of an adequate terminology to distinguish the forms that manuscript collections can take has resulted in frequent looseness of categorisation. Terms like 'anthology' and 'miscellany' have tended to be used interchangeably, with others such as 'commonplace book' often invoked with misleading imprecision. Any terminological debates must be based on an understanding of the processes by which different texts have been brought together, particularly when more than one manuscript preserves identical or very similar collocations. (Boffey \& Edwards 2015: 264)

The intention or plan on the side of the compiler (or compilers) presents us with one of the most difficult and fascinating tasks: Was there an intentionality? Was there a plan? If so, we must also think about the audience this material was targeted for. To study the manner in which the volume was composed and the materials found tells a story about intentionality and audience, and helps to stablish the chronological and social flux of textual transmission.

Although multi-text codex is a more neutral term as we have suggested above, miscellany and anthology connect directly with the intentionality of the scribe/compiler, and from this point of view, Lerer (2003: 1255) indicates that " $[\mathrm{t}]$ here is much debate on whether medieval manuscripts are anthologies or miscellanies - on whether they are volumes guided by a critical intelligence or largely haphazard or practical assemblies of material". This author introduces in the same article what he calls the "anthologistic impulse": this is, when the idea of the anthology is thematically present in the texts (Lerer 2003: 1255). The ultimate question then is related to the understanding of what the compiler's will is in terms of audience, what there is behind his "anthologistic impulse". Many factors can affect this intentionality:

Quite simply, in any given locale, even a metropolis, one cannot be certain that exemplars of any given texts were available. As a result, manuscript compilers, when they acquired an exemplar for any desired text, could not be certain that 
they could gain access to it a second time. Thus, they were constrained to make the fullest imaginable use of any book that came to hand, and their planned core selections would come to coexist with other items. Difficulties of textual supply, as numerous studies indicate, contribute to the miscellaneous, not to say random, appearance of many Middle English books. (Hanna 1996: 47)

Despite the different motivations for the compilation process, the order of the texts may be one of the clues, as the idea of anthology is related to the arrangement of the textual bulk. The classification of the material by genres or themes arises as one of the most problematic but also most fascinating challenges of this type of analysis. To this aim, another author (Stemmler 2000) proposes a taxonomy to attempt a differentiation between these two main labels, explaining that in many cases this differentiation may not be applied strictu sensu. In medical or scientific compilations - as it is the case with MS 3160 of the Sloane Collection - the "anthologistic impulse" may be clearly present, even if it can also be labelled as a miscellaneous volume. It is my aim to demonstrate that this "impulse" or intentionality is part of the primary origin of the material, not only in this manuscript but potentially in the rest of the related manuscripts. To this aim, not just the thematic strand may be fundamental, but also the forming of the different quires or gatherings may also be important in identifying the process and target of the compilation. Whether the volume was composed at the same time or there was some primary material to which the rest of the composition was added by one or different compilers are questions that will help to feed the ground for a solid conclusion.

Concerning the arrangement of contents, Stemmler's proposal in his article 'Miscellany or anthology? The structure of medieval manuscripts' attempts to arrange the materials in MS Harley 2253 and proposes what he calls "potential organising principles for an anthology". These principles would include the classification of the material according to author (one or several), language (Latin/vernacular), form (prose/verse), genre (lyric/narrative/drama), or content (religious/secular). This proposal presents an interesting starting point, although in general terms I seem to agree more with the view of Pratt (2017: 20) which states that "the contents of medieval text collections reveal that the distinctions we habitually make between high and low, religious and profane, entertaining and didactic literature are anachronistic, since cultural products of all kinds sit happily together in multi-text codices." In this line, I think that a careful analysis of the materials, with an extensive analysis of the content, 
should be required in order to uncover possible patterns of organization. To this aim, larger studies are needed and further research awaits until more details provide evidence to develop a proposed taxonomy for this kind of materials.

I have compared the description of the different items in the British Library Catalogue and in the Manuscripts of the West Midlands Catalogue. In this last one, the contents of the volume are described as: "A fifteenth-century miscellaneous manuscript containing mostly English medical texts such as Agnus Castus but also a variety of texts, from a treatise on the deadly sins to charms and homilies." The centrality of the Agnus Castus is a prominent feature in the description, despite the short length of this specific copy.

\section{The Agnus Castus herbal}

The social changes taking place in late medieval England - roughly expanding from the fourteenth to the sixteenth century - entailed an increase in the accessibility to books among secular and professional audiences. This situation derived into a demand for vernacular literature, which in the field of medicine resulted in the extensive production of medical treatises such as herbals. Consisting mainly of translations and adaptations of traditional Latin works, what these treatises lack in originality they make up in scholarly interest, as they are key to understand the emergence of a middle-class audience whose concerns were better addressed in the vernacular (Keiser 2008). A representative example of these writings is the Middle English herbal known as Agnus Castus. This herbal takes the name after the first plant that appears in the collection of herbs and their medicinal uses, normally followed by recipes, which provided "a handy textbook in case of illness or accident" (Brodin 1950: 11). Despite not being as well-known as some of its contemporary equivalents (e.g. Macer or Circa Instans), this text seemed to enjoy great popularity in medieval England: no less than forty-two copies of the work have been identified in medieval manuscripts, to which more than twenty printed versions should be added. This stands for a very important reason to study the transmission and impact of this text.

An important number of the copies of this herbal belong to the British Library's Sloane collection of manuscripts, being part of "amalgamations of varying textual content" (De Schepper 2011: 27); this is, miscellanies. Accordingly, we find the Agnus Castus herbal surrounded by a diversity of 
texts, the majority of which are of medical nature. These include treatises on astrology, urinoscopy, botany, or on particular diseases, as well as recipes, charms and homilies, among others, as it will be referred to below. This text, as it has already been pointed out, was widely disseminated - circulating extensively-, as the forty-two identified copies in Middle English attest. However, the importance of the Agnus Castus herbal should not diminish the relevance of the rest of the material contained in the codex, and it is our intention that describing the contents of this manuscript will shed some light in order to assess this point. As Bouwmeester (2017: 57) indicates:

Scholars characterising medieval multi-text codices often focus largely on the first and/or longest text in the manuscript. [...] neither the size of an individual text, nor its place within the collection solely determines or predicts its relevance for interpreting the compilation as a whole.

In spite of its apparent popularity, Agnus Castus has received limited scholarly attention. In fact, the text only counts with one critical edition performed by Gösta Brodin in 1950 and is mentioned a few times in research carried out by scholars such as Linda E. Voigts or George R. Keiser. Among other issues, these scholars have stressed the interest of individually studying each of the Agnus Castus copies for the ways in which they are conflated with other herbals (Keiser 2005), or because of the association of one of the manuscripts containing it - British Library, MS Sloane 2948 - with the collection of related manuscripts known as the 'Sloane group' (Voigts 1990), as it can be seen in Table 1 below.

The issues raised by the two latter scholars would be in line with the interests of the so called 'New Philology'. Since its advent in the 1990s, this discipline has called for the necessity of studying medieval manuscripts as cultural artefacts in which both the textual and paratextual elements, as well as the surrounding works, play an important role in the form and meaning of the texts (Driscoll 2010). In this sense, it is claimed that a study of a manuscript as a physical object is key to understanding the ways, reason and purpose why a particular audience would engage with that text at a specific moment and place in time (Driscoll 2010). Thus, following the lines of the research opened by the scholars mentioned above, as well as by the field of New Philology, it seems appropriate to claim that the main interest of the Agnus Castus herbal lies also in what its belonging together with other texts (i.e. its being part of 
Table 1. Copies of the Agnus Castus text in the Sloane Collection

\begin{tabular}{|l|l|}
\hline 17. Sloane 2407 & f. $5^{\mathrm{b}}(c .1500)$ \\
\hline 21. Sloane 5 & $\begin{array}{l}\text { ff. } 13^{\mathrm{a}}-57^{\mathrm{a}} \text { (Conflated with Lelamour's Macer, [238] below, } \\
\text { c. } 1465)\end{array}$ \\
\hline 22. Sloane 7 & ff. $30^{\mathrm{a}}-33^{\mathrm{b}}(1475-1500)$ \\
\hline 23. Sloane 120 & ff. $1^{\mathrm{a}}-61^{\mathrm{b}}($ c. 1450$)$ \\
\hline 24. Sloane 135 & ff. $90^{\mathrm{a}}-112^{\mathrm{a}}$ (Eng. and Latin; $\left.1500-1525\right)$ \\
\hline 25. Sloane 297 & ff. $2^{\mathrm{a}}-6^{\mathrm{b}}, 13^{\mathrm{a}-\mathrm{b}}(14$ cent.) \\
\hline 26. Sloane 962 & ff. $249^{\mathrm{a}}-251^{\mathrm{b}}$ (fragment: 15 cent.) \\
\hline 27. Sloane 1315 & ff. $70^{\mathrm{a}}-87^{\mathrm{b}}($ c. 1500$)$ \\
\hline 28. Sloane 2460 & ff. $2^{\mathrm{a}}-33^{\mathrm{b}}(15$ cent. $)$ \\
\hline 29. Sloane 3160 & ff. $99^{\mathrm{a}}, 101^{\mathrm{a}-\mathrm{b}}(15$ cent. $)$ \\
\hline 30. Sloane 3489 & ff. $12^{\mathrm{a}}-28^{\mathrm{a}}(1450-1500)$ \\
\hline
\end{tabular}

different miscellanies) can tell us about it and its owners and readers, than in a critical assessment of the text itself. In addition, its continuation in an abundance of printed editions from the sixteenth century onwards attests for the importance of this text in the context of medieval and early renaissance England.

Considering all the issues mentioned above, the aim of the wider project is to study the Agnus Castus following the thread of the New Philology, and therefore placing our focus on both the textual as well as the paratextual (codicology and miscellanies) dimensions of the work. However, because of the difficulty of handling a number of copies as high as forty-two, and because of our particular interest in the botanical or medical nature of the miscellanies in which the text is contained, only the manuscripts belonging to the Sloane Collection in the Department of Manuscripts at the British Library will be considered in further research, beginning with the case of MS Sloane 3160 in this article. Not only does this collection include some of the most recently identified copies of the work, but it is also considered as "the richest source of scientific and medical writings from Medieval England" (Voigts 1990: 26). The long-term objectives of this project would aim at creating a picture of the manuscript contexts of the work, i.e. to identify its readership -its audience, their socio-cultural contexts and their connections-, as well as to examine its reception -its dialectal and geographical distribution - and circulation. Ultimately, a study of this nature will help us to understand the reach and impact of the Agnus Castus, and thus allow for its location within the broader 
history of medicine, shedding light upon our understanding of the role of pre-Linnaean botany in the medical practices and the nature and influence of medical thought in late medieval and early renaissance times.

\section{MS Sloane 3160: Contents and some thoughts on its collective meaning}

This article is focused on the description of the contents of MS Sloane 3160 and its connection with the transmission and impact of the Agnus Castus text. MS Sloane 3160 is a codex on paper and it contains 173 folios. Two catalogues have been consulted in order to contrast the information about the content arrangement with the manuscript itself: the British Library Catalogue (BLC) and the Manuscripts of the West Midlands Catalogue (MWMC). Most of the items appear in both sources, but there are some minor differences. Also, the location of some texts was not precise and some material had not been included, as it will be indicated below. In Table 2 there is a list of the items as they appear in MS 3160.

We have also included the information related to language and form, partially following Stemmler's proposal above, with the exception of genre. In this case, all the material (with the exception of religious texts) can fall clearly into the medical and/or scientific category. However, a further distinction of different subtypes in the classification of the rest of the manuscripts involved would present us with interesting information.

The table of contents appearing in the first place shows an incomplete description of the homilies, and an incorrect numbering. The first text is a religious one, a homily of the seven deadly sins, a very popular and extended text. There are two different page numberings, the first corresponding to the item in which the text was first copied, and the second - number fourwould correspond to the rearranging of the material when it was included in the miscellanea. The second item is also religious. It is entitled 'Homilies for saints', and starts with the incipit "the grace and the goodness of almyty god thurgh the preyers". Together with the homilies for the seven sins, these two are the only religious material present in the volume. A possible explanation would be that both texts may show an intimidatory function and a warning to the practice of several vices, which clearly lead to sickness and death. 
Table 2. Items contained in MS Sloane 3160

\begin{tabular}{|c|c|c|c|}
\hline Items & Location & Form & language \\
\hline 1. On the seven deadly sins & ff. $1-25 \mathrm{v}$ & prose & English \\
\hline 2. Homilies for saints & ff. $26 \mathrm{r}-88 \mathrm{v}$ & prose & English \\
\hline 3. Urine (Flasks) & ff. $89 \mathrm{r}-90 \mathrm{v}$ & drawing & English/Latin \\
\hline 4. Treatise on urines & ff. $91 r-96 r$ & prose & English \\
\hline 5. An Herball Latin \& English & ff. $97 \mathrm{r}-98 \mathrm{v}$ & glossary & English/Latin \\
\hline 6. Medical recipes & f. $99 a$ & prose & English \\
\hline 7. Agnus Castus & f. $99 \mathrm{~b}$ & prose & English \\
\hline 8. Medical recipes (scribbles) & f. $101 \mathrm{r}$ & prose & English \\
\hline 9. Herbal & f. $101 \mathrm{v}$ & prose & English \\
\hline 10. Virtues of herbs & ff. $102 \mathrm{r}-108 \mathrm{v}$ & prose & English \\
\hline 11. Medical recipes & ff. $109 r-125 \mathrm{v}$ & prose & English \\
\hline 12. Tractatulus de regimine sanitatis & ff. $126 \mathrm{r}-127 \mathrm{v}$ & prose & Latin \\
\hline 13. Medical recipes & f. $127 \mathrm{v}$ & prose & English \\
\hline $\begin{array}{l}\text { 14. Teaching of Galian the leche. On } \\
\text { the best months to drink and eat }\end{array}$ & -- & prose & English \\
\hline $\begin{array}{l}\text { 15. Bloodletting. The best months to } \\
\text { let blood }\end{array}$ & f. $151 \mathrm{r}$ & prose & English \\
\hline $\begin{array}{l}\text { 16. Treatise on the best times of the } \\
\text { year to eat meat and drink and } \\
\text { also for bloodletting }\end{array}$ & f. $151 \mathrm{v}$ & prose & English \\
\hline $\begin{array}{l}\text { 17, 18, 19. Medical recipes and } \\
\text { charms of different sorts }\end{array}$ & ff. $152 \mathrm{r}-170 \mathrm{v}$ & prose & English \\
\hline $\begin{array}{l}\text { 20. A promise to repay in time } \\
\text { (MWMC) }\end{array}$ & f. $173 \mathrm{v}$ & prose & English \\
\hline
\end{tabular}

After two religious items, practical medicine appears in the form of flasks or Jordans, which is the name typically given to the containers where urine was kept and studied, according mainly to the color or colors, each of them exhibiting a property which would describe and/or predict the individual's health. We find a total of twenty-four of them. In this case, the Jordans are presented depicting the color in Latin at the top and giving a description of the color and causes. The first example reads "subrubea", and the text below "a fever corrupt blod a vaynes brokyn in the bak". Following the Jordans and the description of colors and sickeness is common to have a treatise on urines, to 
complement further knowledge in this field. Item four accomplishes this expectation, beginning "These are the tokens of color in uryne."

The next item or text is a bilingual herbal Latin and English and, as expected, will be followed by more similar material. This thematic group is going to be one of the most representative groups in the manuscript, including of course one of the copies of the Agnus Castus, which follows to the first Herball. The text known as Agnus Castus was catalogued in the MWMC as in folios $99 \mathrm{r}$ to 100r. After revising the manuscript, it appears that $99 \mathrm{ra}$ contains medical recipes (for headache and other aches). These are not included in the description of the catalogues consulted, and it is in $99 \mathrm{rb}$ that the Agnus Castus will be found. The fact that both texts present an almost identical mise en page and in the same script may have led to be considered one. Also in item eight, the MWMC describes the presence of an herbal in $101 \mathrm{r}-\mathrm{v}$. However, the herbal does start in 101v, but not in 101r where we find recipes with some scribble at the end, and the phrase "probatum est", an ephicacy phrase, very commonly used in recipes. The reason why text in $101 \mathrm{r}$ is not found in the descriptions of the catalogues is due to the fact that it does not bear significative material and may probably be a later addition. Two more herbals complete this section of thematically-related group of texts: in $101 \mathrm{v}$, a text which starts "her is an herbe that is called imarie", followed by item nine, Virtues of herbs, with the Incipit "Here men may se pe vertue of herbus whiche ben hote ande wheche byn cold For how many thenges pi beyn god."

We change now from herbs to medical recipes, noting that the script is the same. The following folios $(109 \mathrm{r}-125 \mathrm{v})$ contain diverse recipes, the first being "for the migreyne in pe hede". In the MWMC this first recipe for migraine is said to be "for Mr Whittenton" added in later script.

Item number twelve is described in both catalogues as Tractatulus de regimine sanitatis editus aud montem perserulanum anno 1281. In the BLC additional information is found, connecting the text with Montpellier, France. Most probably, we may have here a copy of the Regimine Sanitatis by the famous doctor Arnau de Vilanova, a canonical text that would suit the volume, as it is a compendium of advices on how to keep healthy. This text is followed by more recipes. And the next item, where different scripts are found, is identified as a text containing "teaching of Galian the leche. On the best months to drink and eat". The last part of the volume is the most miscellaneous in the original sense. Several treatises on bloodletting, recipes and charms alternate. The MWC says that folio $151 \mathrm{r}-\mathrm{v}$ contains an item with the incipit "here begynnys the techynge and the rulyng how a man schuld governe hym 
thru the zer of methus and drynkus and blode lettyng", which would actually corresponds to $151 \mathrm{v}$. Text in $151 \mathrm{r}$ is actually a text on bloodletting beginning "The fyrst daie of the new mone gode is to lette blode". Items fifteen, sixteen and seventeen contain different recipes and charms, with some prayers also included. Finally, in folio $173 \mathrm{v}$, we find some scribble which corresponds to what the MWMC identifies as a promise to repay in time.

Once all texts have been described, it becomes fundamental to enquiry about issues such as the main thematic strands and the collective meaning of the arrangement. It is clear that the Agnus Castus is not precisely the longest text, but it is certainly one of the most canonical and easily recognized by the audience that would read and use the material. Also, the importance in the arrangement of this text relies in the dialogue or collective meaning that conforms when presented with the rest of them. The audience of the miscellaneous volume would receive the text by naturally associating it with the rest of the manuscript contexts, and it would not fit into the medieval mind to extract or separate the Agnus Castus from the rest of the medical material, because it simply belongs there. The flux of textual transmission was a collective mission, and it is not accurate to think that the text was received and circulating without the company of more meaningful material, as it is normally described in critical editions. Therefore, I would like to emphasize the importance of looking at these manuscript contexts in detail, as much knowledge about impact and reception can be gained.

In this manuscript, we have therefore a small group of religious items, followed by a prominent compendium of herbals, urine treatises, bloodletting and medical recipes as a convenient addition when necessary. It primarily responds to the expectations we would have -including the religious material - and the thematic blocks would reflect the "impulse" guiding the responsible (one or many) in the final arrangement:

It is generally accepted that the composition of a miscellany, be it cumulative or organic, responds to an intellectual organisation that predates its actual collection, resulting in a unique material entity which turns out to be the consequence of a project, of a conceptualisation. (Van Hemelryek 2011: 292)

Miscellaneous collections need to be described, analyzed and interpreted as a reciprocal entity, in which all texts are going to be part of their transmission and influence their reception. These co-texts should not be neglected when studying the individual texts, and editions or studies should make reference to 
manuscript contexts. These contexts are also meaningful, as Pratt (2017: 34) quite recently stated, these contexts are also meaningful because:

One might argue that each codex is a unique artefact, with its text collection providing a unique set of possible readings. However, it is possible to make some generalisations about these manuscripts, both with linguistic and cultural areas, and across them, although the evolution of these books from the thirteenth to the fifteenth centuries must also be taken into account.

\section{Conclusion and further research}

Studying miscellaneous material shows the collective mind of scribes and compilers when it comes to textual gatherings. The so-called "anthologistic impulse" may have been present in a more or less conscious degree in the design of these materials, and was certainly the most frequent plan in medieval libraries. With respect to medicine and science, medical miscellanea would normally contain texts for prognosis, to identify the medical problem, and texts for remedies - together with charms - as it is the case of this volume. All together it shows also a concern for including prayers and religious texts, religion being part of the cure in these times. The fact that the homilies of the seven sins are there in the first place tells us that this material played an important and relevant part. This was very popular and circulated extensively, and homilies warned about the vices that led to sickness. This would add the spiritual dimension to the whole volume, which in fact, was of a very pragmatic nature: if you avoided gluttony, you would probably avoid diseases related to it. We can conclude that MS Sloane 3160 is composed of items that would correspond to a medical or scientific compilation or vademecum of the time. Following Lerer's concept of "the anthologistic impulse", the arrangement shows that the compiler gathered most of the material according to a certain plan and for a certain audience. There are several texts with the same script, continuously arranged, which suggest these copies were being arranged in that specific order. A more thorough study of the codicological properties would contribute to confirm this. Additionally, the search for patterns could benefit from a detailed comparison of more manuscripts. Although the idea of proposing a taxonomy for their study could be too ambitious, identifying a set of different recognizable patterns would help to 
understand the function of these manuscript contexts. In this line, Van Hemelryek (2011: 293) also points out that:

[...] let us suggest that we ought to make a distinction between the order of a miscellany and its logic: the first echoing the programmatic codicological act, the other calling out the concepts involved in its reception; because, when culture becomes its own object, it subjects itself to constraints that deserve to be further explored.

In terms of further research, the main objectives of the wider project have been already introduced in Section 3. These objectives will help us to understand what kind of audience had authors/copyists/scribes in mind when writing the text, what kind of audience actually recurred to the text and with what purpose, and what the other texts included in the miscellanies say about the text itself and about its audience. Ultimately, this will help us to establish the importance of the text within the history of botany and medicine.

As to the analysis of the manuscript contexts, the Agnus Castus text is as paramount to the miscellanea as any of the accompanying items, but co-texts may help to uncode the flux and impact of this herbal, and therefore their importance and role should not be diminished. Bouwmeester (2017: 57-58) emphasizes the idea that the interplay between all texts is a fundamental issue that is many times neglected in favour of solely studying the longest text in the codex. He encourages researchers to embrace a more global perspective on the study of the miscellanea or multi-text codices and consider all the texts included, as "all too often the meaning of a medieval text is shaped (or influenced) by all its co-texts, regardless of their length". We do agree with this perspective, and further suggest that editions of texts may include a description and short analysis of the material compiled together in the codex, as part of the analysis of the context and its transmission, and the impact of the work. Also Lerer (2003: 1263) points that:

Our pedagogy should reflect this recognition: we should teach our texts with an awareness of the material contexts in which they originally appeared. But we should also recognize that those material contexts are constantly in flux, as texts get copied into new collections, printed books get bound together, and long works or portions of a poet's oeuvre get plucked for beauties in a modern book. 
In this sense, the whole volume would offer a global perspective both for the compiler and the reader and/or practitioner, which would be altered by looking at the items individually, and not collectively.

\section{References}

Boffey, J. \& A. S. G. Edwards 2015: Towards a Taxonomy of Middle English Manuscript Assemblages. In M. Conolly \& R. Radulescu eds. Insular Books. Vernacular Manuscript Miscellanies in Late Medieval Britain. Oxford, Oxford University Press: 263-269.

Bouwmeester, G. 2017: Size Does Not Matter: On Characterising Medieval MultiText Codices. In K. Pratt, B. Besamusca, M. Meyer \& A. Putter eds. The Dynamics of the Medieval Manuscript. Text Collections from a European Perspective. Göttingen, V\&R unipress GmbH: 57-80.

BLC $=$ British Library Catalogue - Browse Collections: Archives and Manuscripts, Sloane Manuscripts (c. $1000-$ c. 1750) Available from:

http://hviewer.bl.uk/IamsHViewer/Default.aspx?mdark=ark:/81055/vdc_10000000 0040.0x00011c\&_ga=2.148417204.264356798.1531156327-117876278.1524556059 [Accessed 25 April 2018].

Brodin, G. 1950: Agnus Castus, a Middle English Herbal: Reconstructed from Various Manuscripts. Uppsala, Lundequistska Bokhandeln.

De Schepper, T. J. E. 2011: The Several Sages: The Late Middle English Herbal in its Genre, Manuscript and Printed Context. (Master's dissertation.) Utrecht, Utrecht University.

Driscoll, M. J. 2010: The Words on the Page: Thoughts on Philology, Old and New. In J. Quinn \& E. Lethbridge eds. Creating the Medieval Saga: Versions, Variability and Editorial Interpretations of Old Norse Saga Literature. Odense, University Press of Southern Denmark: 85-102.

Keiser, G. R. 2008: Vernacular Herbals: A Growth Industry in Late Medieval England. In M. Conolly \& L. R. Mooney eds. Design and Distribution of Late Medieval Manuscripts in England. Rochester, Boydell \& Brewer: 291-308.

Hanna, R. 1996: Miscellaneity and Vernacularity: Conditions and Literary Production in Late Medieval England. In S. G. Nichols \& S. Wenzel eds. The Whole Book. Cultural Perspectives on the Medieval Miscellany. Ann Arbor, The University of Michigan Press: $37-51$.

Lerer, S. 2003: Medieval English Literature and the Idea of the Anthology. PMLA 118.5: 1251-1267.

MWMC = Manuscripts of the West Midlands Catalogue. A Catalogue of Vernacular Manuscript Books of the English West Midlands c. $1300-c .1475$. Available from: www.dhi.ac.uk/mwm/ [Accessed 22 March 2018]. 
Pratt, K. 2017: Introduction. In K. Pratt, B. Besamusca, M. Meyer \& A. Putter eds. The Dynamics of the Medieval Manuscript. Text Collections from a European Perspective. Göttingen, V\&R unipress GmbH: 11-40.

Stemmler, T. 2000: Miscellany or Anthology? The Structure of Medieval Manuscripts: MS Harley 2252, for Example. In S. Fein ed. Studies in the Harley Manuscript. The Scribes, Contents, and Social Contexts of British Library MS Harley 2253. Kalamazoo, Medieval Institute Publications, Western Michigan University: 111-121.

Van Hemelryek, T. 2001: Of Books and Other Miscellaneous Revolutions. Medieval Miscellanies in Context. In K. Fresco \& A. D. Hedeman eds. Collections in Context. The Organisation of Knowledge and Community in Europe. Columbus, The Ohio State University Press.

Voigts, L. E. 1990: The 'Sloane Group': Related Scientific and Medical Manuscripts from the Fifteenth Century in the Sloane Collection. The British Library Journal, $16: 26-57$.

Author's address

Departamento de Estudis Anglesos

Facultat de Ciències Humanes i Socials

GREMI (Grup de Recerca d'Estudis Medievals Interdisciplinars)

Universitat Jaume I

12071 Castelló, Spain

e-mail: resteve@uji.es

received: 11 May 2019

revised version accepted: 10 June 2019 